\title{
ARTIGo \\ 0 efeito da testagem laboratorial nos indicadores de acompanhamento da COVID-19: uma análise dos 50 países com maior número de casos*
}

\section{The effect of laboratory testing on COVID-19 monitoring indicators: an analysis of the 50 countries with the highest number of cases}

\section{El efecto de las pruebas de laboratorio en los indicadores de seguimiento de COVID-19: un análisis de los 50 países con el mayor número de casos}

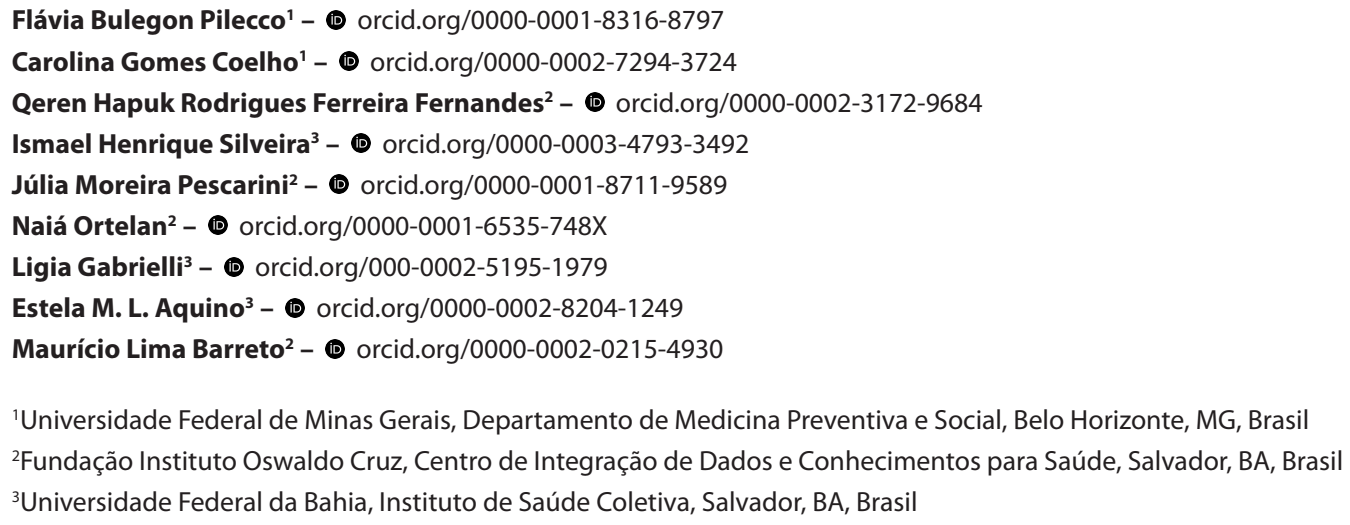

\section{Resumo}

Objetivo: Analisar como a testagem da população influencia os indicadores de saúde usados para monitorar a pandemia de COVID-19 nos 50 países com maior número de casos diagnosticados. Métodos: Estudo ecológico sobre dados secundários, extraídos em 19/08/2020. Foram calculadas incidência acumulada, taxa de mortalidade, letalidade e proporção de testes positivos. Os dados foram descritos e apresentados graficamente, com o respectivo coeficiente de correlação de Spearman. Resultados: A taxa de testagem variou enormemente entre os países. A incidência acumulada e a proporção de testes positivos foram correlacionadas ao número de testes, enquanto a taxa de mortalidade e a letalidade apresentaram correlação baixa com esse indicador. Conclusão: A maioria dos países não testa o suficiente para garantir adequado monitoramento da pandemia, com reflexo na qualidade dos indicadores. A ampliação do número de testes é fundamental; porém, ela deve ser acompanhada de outras medidas, como isolamento de casos diagnosticados e rastreamento de contatos.

Palavras-chave: Infecções por Coronavírus; Indicadores Básicos de Saúde; Incidência; Mortalidade; Betacoronavírus.

* Para a realização do estudo, a autora Qeren Hapuk Rodrigues Ferreira Fernandes recebeu apoio financeiro na forma de bolsa de doutorado, concedida pela Fundação de Amparo à Pesquisa do Estado da Bahia (Fapesb): Processo n 232/2019. 


\section{Introdução}

Desde a identificação do primeiro caso da doença respiratória causada pelo novo coronavírus (coronavirus disease, COVID-19) até 19 de agosto de 2020, foram diagnosticados mais de 22 milhões de casos e notificados 781 mil óbitos pela doença, em todo 0 mundo. ${ }^{1}$

\section{As estratégias de testagem adotadas} influenciam a qualidade dos indicadores de saúde essenciais para o planejamento e execução de ações voltadas ao controle da pandemia.

0 alto poder de disseminação do coronavírus causador da doença, o SARS-CoV-2, e o crescente número de casos reforçam a importância do conhecimento sobre a situação epidemiológica, em um país ou região, para que sejam planejadas as respostas mais adequadas. ${ }^{2}$ Nesse sentido, a realização de testes laboratoriais para diagnóstico da infecção é de fundamental importância para se conhecer a magnitude da infecção, seu controle e monitoramento.

Os testes podem servir para (i) a identificação da presença do vírus em atividade, pela detecção de seu genoma em amostras do trato respiratório superior e inferior, sendo mais comumente adotado o teste de reação em cadeia da polimerase via transcriptase reversa em tempo real (real-time reverse transcription polymerase chain reaction [real-time RT-PCR]); os testes também permitem (ii) a detecção de anticorpos específicos em amostras de sangue, cuja presença é indicativa de infecção prévia, sendo estes últimos os testes sorológicos, operacionalmente mais simples e frequentemente usados em inquéritos epidemiológicos. ${ }^{3}$

Apesar da importância da testagem para o controle da infecção pelo SARS-CoV-2, as estratégias adotadas variam entre os diferentes países e fases da epidemia. ${ }^{4}$ Países asiáticos já atingidos por outras epidemias respiratórias, como Taiwan e Hong Kong (China), e outros, como Nova Zelândia, Islândia, Mônaco e Alemanha, têm adotado estratégias mais amplas, geralmente a testagem de suspeitos com sintomas leves, para identificar e isolar os casos, e rastrear seus respectivos contatos.
Outros países, em função de restrições orçamentárias, do tamanho populacional ou do projeto de governo em exercício, adotaram estratégias mais limitadas..$^{5}$ Nesse caso, a testagem tem se restringido a pessoas com sintomas graves, às que tiveram contato com um caso confirmado e àquelas pertencentes a grupos de 'alto risco'; ou são combinados esses e outros critérios. ${ }^{6}$ Foi o que aconteceu nos países europeus mais atingidos pela epidemia, nos Estados Unidos e no Japão, e em países de baixa e média renda da Ásia, África e América Latina.

As estratégias de testagem adotadas influenciam as estimativas do número de infectados e de óbitos pelo vírus SARS-CoV-2. Assim, as estratégias adotadas afetam a qualidade dos indicadores de saúde essenciais para o planejamento e execução de ações voltadas ao controle da pandemia., ${ }^{2,7}$

0 objetivo deste artigo foi analisar como a testagem da população influencia os indicadores de saúde utilizados para monitorar a pandemia de COVID-19 nos 50 países com maior número de casos diagnosticados.

\section{Métodos}

A presente investigação consiste em um estudo ecológico utilizando dados secundários. Foram selecionados os 50 países com maior número de casos diagnosticados de COVID-19, reportados até o dia 19 de agosto de 2020, data em que a extração de dados foi realizada. Dados de testagem foram obtidos do sítio eletrônico Worldometers (https://www.worldometers. info/coronavirus/).

0 Worldometers é um website que analisa, valida e agrega dados de milhares de fontes em tempo real, incluindo sítios oficiais de ministérios da saúde e/ou demais instituições governamentais, contas de mídia social de autoridades governamentais e, eventualmente, informações provenientes de canais de notícias importantes e confiáveis, cujos dados estão disponíveis antes de serem publicados nos sítios oficiais. No Worldometers, as informações disponíveis não discriminam o tipo de teste realizado (RT-PCR ou sorológico), razão por que neste documento, ao se referir à testagem para SARS-CoV-2, fala-se tanto de testes por RT-PCR quanto de testes sorológicos.

0s casos e óbitos por COVID-19 foram obtidos no website do Centro Europeu de Controle de Doenças (European Center for Disease Control). 
A definição de caso varia de país para país: alguns consideram 'caso confirmado' apenas aquele com diagnóstico laboratorial, enquanto outros consideram como 'caso de COVID-19' tanto aquele que recebeu diagnóstico laboratorial quanto o identificado por critério clínico-epidemiológico. Neste documento, são considerados 'casos diagnosticados de COVID-19', não importando o critério diagnóstico. As estimativas populacionais de 2019, por sua vez, foram obtidas do Banco Mundial (https://data.worldbank.org/indicator/ SP.POP.TOTL).

A partir desses dados, foram calculados os seguintes indicadores:

a) taxa de testagem (número de testes realizados, por milhão de habitantes);

b) incidência acumulada (número de casos diagnosticados dividido pela população local, apresentado por milhão de hab.);

c) taxa de mortalidade (número de óbitos pela doença dividido pela população local, apresentado por milhão de hab.);

d) taxa de letalidade (número de óbitos por número de casos registrados, em \%); e

e) proporção de testes positivos (número de testes positivos por número de testes realizado, em \%).
Foram realizadas análises descritivas e representação gráfica (diagrama de dispersão) da incidência acumulada, taxa de mortalidade, letalidade e proporção de testes positivos, em relação à taxa de testagem de cada país. Para cada gráfico de dispersão, estima-se uma reta linear representativa dos valores esperados do indicador analisado para a taxa de testagem. A essa reta sobrepõem-se um intervalo de confiança de $95 \%$ $\left(\mathrm{IC}_{95 \%}\right)$, representado na cor cinza. A escala utilizada nos gráficos, linear ou logarítmica, foi selecionada para permitir a melhor visualização das tendências.

Os dados não apresentaram distribuição normal (Shapiro-Wilk: p-valor $<0,001$ ), motivo pelo qual 0 coeficiente de correlação de Spearman foi utilizado para avaliar as correlações entre 0 número de testes e os indicadores de saúde selecionados (incidência acumulada, taxa de mortalidade, letalidade e proporção de testes positivos). Os dados foram processados e analisados com o uso do pacote estatístico ggplot $2,{ }^{8}$ no software R versão 4.0.1.9

\section{Resultados}

Na Figura 1, observa-se a distribuição do número de testes realizados por milhão de hab. Um primeiro

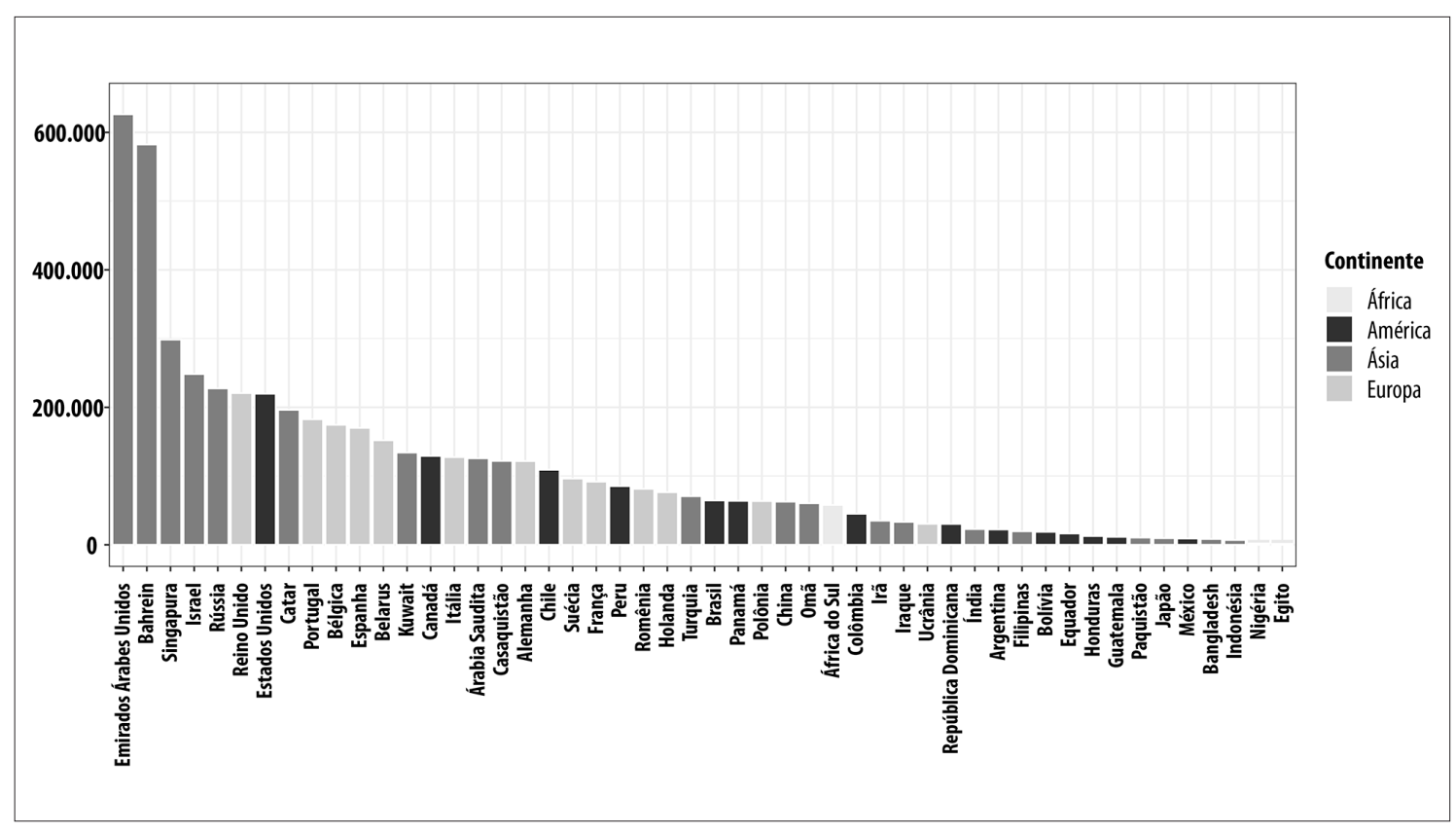

Figura 1 - Número de testes para diagnóstico do vírus SARS-CoV-2 por milhão de hab., nos 50 países com maior número de casos de COVID-19, em 19 de agosto de 2020 
grupo de países que realizaram mais de 100 mil testes por milhão de hab. foi composto, em sua grande maioria, por países da Europa Ocidental, países da Ásia com elevado produto interno bruto (PIB) per capita, Canadá, Estados Unidos e Chile. Emirados Árabes Unidos e Bahrein destacaram-se nesse grupo, por terem apresentado coeficientes de testagem muito superiores aos demais, acima de 550 mil testes por milhão de hab. Suécia, França, Holanda, Turquia, Romênia, Polônia, Brasil, Peru, Panamá, China, Omã e África do Sul distribuíram-se em um bloco intermediário, entre 100 e 50 mil testes por milhão de hab. Com menor número de testes realizados, ou seja, menos de 50 mil testes por milhão de hab., estão a maioria dos países latino-americanos, países asiáticos com menor PIB per capita e Japão, além da Nigéria e do Egito.

A Figura 2A mostra que a incidência acumulada aumentou com 0 número de testes realizados por milhão de hab. ( $\rho x y=0,558)$, e a Figura $2 B$, a baixa correlação entre a mortalidade e 0 número de testes realizados por milhão de hab. ( $\rho x y=0,253)$. A maioria dos países latino-americanos apresentaram tanto incidência acumulada quanto taxa de mortalidade acima do esperado, segundo suas taxas de testagem. Quanto aos europeus desta análise, apresentaram incidências acumuladas próximas do esperado para países com a respectiva taxa de testagem; sua taxa de mortalidade, contudo, foi superior à esperada, de forma geral. A maioria dos países asiáticos avaliados, constituintes do grupo que mais testou para COVID-19, apresentaram uma incidência acumulada próxima ao esperado, porém uma taxa de mortalidade abaixo, quando comparada à de outras nações com as mesmas taxas de testagem.

A Figura 2C mostra que não houve correlação entre taxa de letalidade e testagem por milhão de hab. ( $\rho x y=-0,057)$. Países europeus, como França, Itália, Bélgica, Holanda e Reino Unido, e o México, na América do Norte, destacaram-se por apresentarem letalidade muito superior à esperada, segundo suas taxas de testagem.

Por fim, na Figura 2D, é possível observar a diminuição da proporção de testes positivos com 0 aumento do número de testes efetuados ( $\rho x y=-0,626)$. Países como Egito, Bolívia e México apresentaram alta proporção de testes positivos. No Brasil, tal proporção foi de $24,5 \%$ para o período estudado.

\section{Discussão}

Os resultados deste estudo indicam que, entre os 50 países com maior número de casos diagnosticados, a taxa de testagem variou enormemente. Houve países que realizaram mais de 550 mil testes por milhão de hab., como os Emirados Árabes Unidos e 0 Bahrein, e outros que realizaram menos de 1.350 testes por milhão de hab., como 0 Egito. Os achados mostram que alguns indicadores epidemiológicos, a exemplo da incidência acumulada e da proporção de testes positivos, estão correlacionados ao número de testes realizados para o diagnóstico da infecção, enquanto a taxa de mortalidade e a letalidade apresentaram baixa correlação com esse indicador.

Alguns países, entre os 50 observados, referiram baixa taxa de testagem da população. São países de baixa e média renda, situados na América Latina, Ásia e África, cuja epidemia iniciou-se mais recentemente, quando comparados aos países europeus. A exceção coube ao Japão. 0 baixo número de testagem efetuada por milhão de hab. nesses países pode estar relacionado à priorização de recursos, direcionados apenas para os casos graves, como ocorre no México, ${ }^{10}$ ou à própria dificuldade em expandir a capacidade de testagem, como ocorre no Egito ${ }^{11}$ e na Nigéria. ${ }^{12}$

Em contrapartida, destacam-se países que já aplicaram um número de testes correspondente a mais de metade de sua população, como os Emirados Árabes Unidos e o Bahrein. É possível que experiências anteriores desses países com a síndrome respiratória do Oriente Médio (Middle East Respiratory Syndrome Coronavirus [MERS]) conferissem a eles um melhor preparo para acolher as demandas geradas por surtos posteriores de vírus respiratórios, caso do SARS-CoV- $2 .{ }^{13}$ No entanto, a taxa de testagem elevada não impediu que esses países estivessem entre os 50 com maior número de casos. Isto, possivelmente, deve-se à falta de conjugação da ampla testagem com medidas de controle não farmacológicas, embora a recente queda do número de casos diários nesses países ${ }^{1}$ possa indicar que a testagem mais abrangente adotada contribui para o declínio observado.

Os dados analisados mostraram uma correlação moderada entre a taxa de testagem e a incidência acumulada. É de se esperar que quanto mais testes sejam realizados, mais casos sejam diagnosticados. A China parece despontar como uma exceção a esse 
padrão: apesar de ter ampliado sua estratégia de testagem, permitindo a execução de RT-PCR mesmo para pessoas com baixa suspeita de COVID-19, uma expressiva baixa incidência acumulada foi mantida, em comparação aos demais países com a mesma taxa de testagem. Este comportamento pode ser explicado pela conjugação do crescente número de testes diagnósticos aplicados com o isolamento de novos casos. ${ }^{14}$ Esse tipo de comportamento também foi notado em países bem-sucedidos no combate à epidemia, embora não figurem entre os 50 com maior número de casos, como a Nova Zelândia, ${ }^{15}$ a Coreia do Sul ${ }^{6}$ e a Islândia. ${ }^{16}$ No caso da China, experiências anteriores com a MERS e a síndrome respiratória aguda grave (do inglês, Severe Acute Respiratory Syndrome [SARS]) também podem ter contribuído para tal padrão, diferenciado dos demais..$^{14}$ Além disso, é importante considerar que, em fevereiro de 2020, período em que a China alcançava o maior número de casos diários até o momento, os testes diagnósticos desenvolvidos eram submetidos a procedimentos de aprovação de emergência. Tal fato pode ter impactado em um percentual considerável de resultados falso-negativos, o que pode também explicar, ainda que parcialmente, a menor incidência acumulada da China. ${ }^{14,17}$

A taxa de mortalidade foi correlacionada de forma positiva com a testagem, assim como a incidência acumulada, porém com menor magnitude. Alguns países europeus, cuja incidência acumulada esteve dentro do esperado, apresentaram mortalidade por COVID-19 acima de países com taxas de testagem equivalentes. Diversos fatores poderiam concorrer para esse resultado, como a idade mais avançada da população e consequente presença de comorbidades. ${ }^{18,19}$ A mortalidade mais alta nos países da Europa Ocidental também pode estar relacionada a uma melhor investigação dos óbitos que dos casos. ${ }^{20}$ Outrossim, uma mudança no critério de definição de óbito ou a dificuldade em atestar o óbito por COVID-19 pode interferir nessas estimativas. Um exemplo dessa possibilidade é a Itália, onde pesquisadores relataram dificuldade para diferenciar mortes diretamente causadas por SARS-CoV-2 de mortes por outras causas, em indivíduos apenas infectados pelo vírus. Tal fato se atribui à presença de comorbidades importantes na grande maioria dos diagnosticados com COVID-19 idos a óbito: 98,8\% tinham ao menos uma comorbidade; e $48,6 \%$, três ou mais. ${ }^{21}$
No entanto, ao compararem as taxas de mortalidade, deve-se considerar outros fatores, como 0 momento da epidemia. É possível perceber que países cuja testagem é mais ampla, como China e Singapura, apresentam taxas de mortalidade comparáveis àquelas da Nigéria, o segundo país que menos testou entre os 50 com maior número de casos, avaliados neste estudo. Uma taxa de mortalidade baixa não necessariamente reflete êxito no controle da pandemia. ${ }^{22}$

A letalidade teve baixa correlação com a testagem. Se tanto os casos (incluindo assintomáticos) quanto os óbitos fossem apropriadamente identificados, esperar-se-ia uma letalidade por COVID-19 próxima a $1 \%{ }^{23}$ salvo exceções, o que se vê é a grande maioria dos países a referir uma taxa acima desse valor. Europeus, como França, Itália, Reino Unido, Bélgica e Holanda, além do norte-americano México, apresentam esse indicador acima de $10 \%$.

A letalidade é influenciada pela estrutura demográfica (países com maior proporção de idosos tendem a apresentar maior letalidade) e pela organização do sistema de saúde nacional. Uma saúde pública mais bem preparada para identificar e isolar os casos e tratar aqueles que necessitam responderá por menores taxas de letalidade. E países que identificam melhor os óbitos do que os casos tendem a apresentar maior letalidade. ${ }^{20}$ Em relação a esse indicador, o Brasil se encontra próximo do esperado para sua taxa de testagem. Dado o contexto atual do país, é possível supor que 0 resultado brasileiro decorra de subnotificação generalizada, tanto dos óbitos quanto dos casos de infecção por SARS-CoV-2.

Em relação à proporção de testes com resultado positivo, foi observado que quanto maior a taxa de testagem, menor essa proporção. Alguns países, como Egito, México e Bolívia, apresentaram alta proporção de testes positivos, acima de 40\%, um dado indicativo de que são testados apenas os doentes mais graves, aqueles que procuram assistência médica ambulatorial ou hospitalar. Além disso, a elevada proporção de testes positivos aponta que o país não é capaz de mensurar a real dimensão da disseminação do vírus em seu território. ${ }^{24}$

A Organização Mundial de Saúde (OMS) recomenda: para um país iniciar a flexibilização da quarentena e do distanciamento social, a proporção de testes positivos deve ser de, no máximo, $5 \%$, pelo período mínimo de 14 dias. ${ }^{24}$ 0s países latino-americanos 

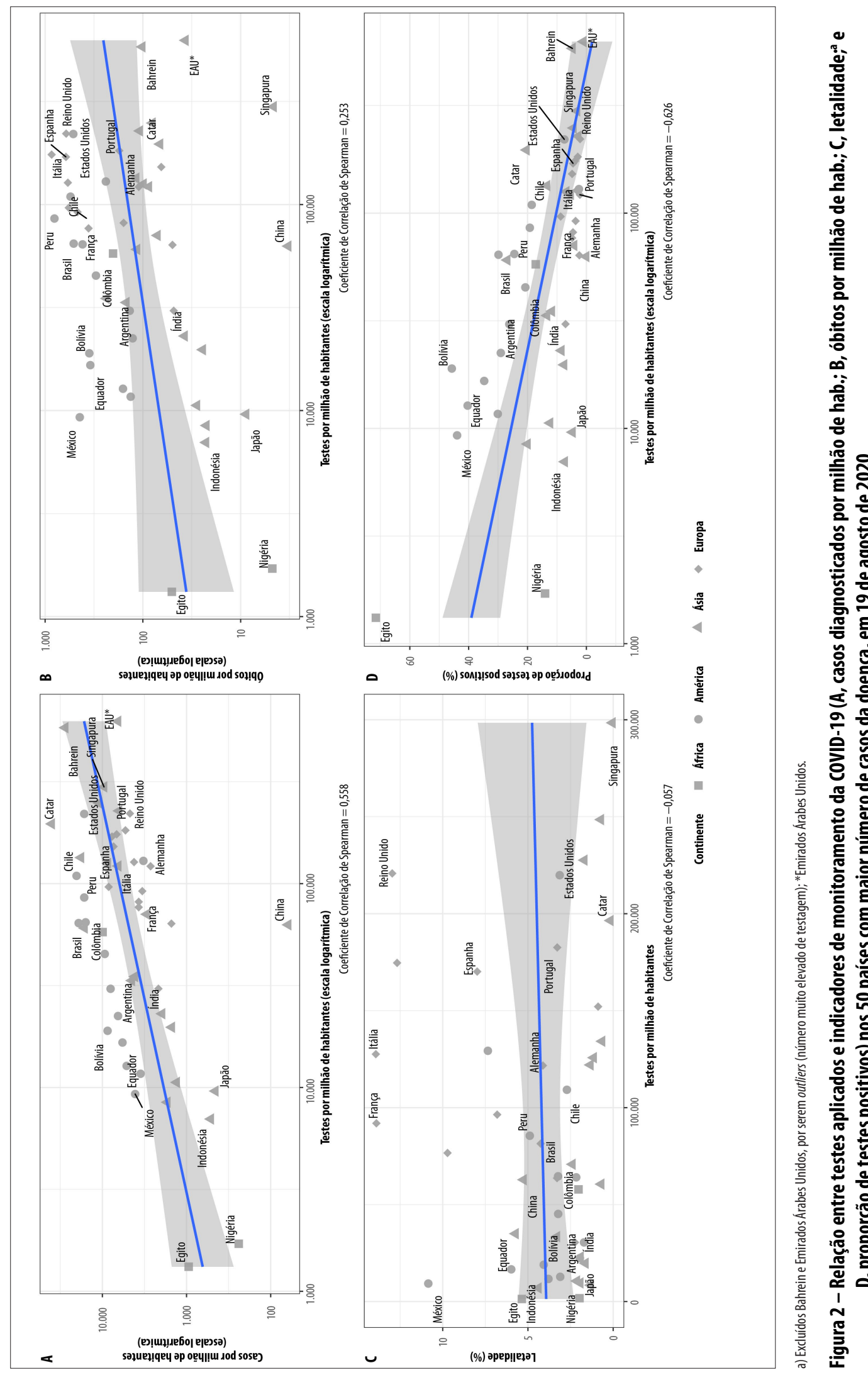
aparecem distantes de cumprir tal meta, haja vista todos apresentarem cerca (ou acima) de $20 \%$ de testes positivos. Exemplos dessa relação são México e Brasil, que enfrentam problemas semelhantes, a começar da negação do governo federal em reconhecer a pandemia enquanto problema de saúde pública, e por conseguinte, não a enfrentar por meio de políticas de saúde, coordenadas interministerialmente, juntamente com as unidades de sua federação. ${ }^{25,26}$ Os dois países testam apenas os casos graves, a despeito de 0 Brasil vir aumentando, lentamente, sua taxa de testagem: no momento da conclusão deste relato, 64.593 testes por milhão de habitantes. 0 México (9.281 testes por milhão de hab.) continua a ser um dos países que menos testa entre os $50 \mathrm{com}$ maior número de casos diagnosticados. ${ }^{22}$ Mesmo em um cenário de testagem aquém do necessário, com alto percentual de testes positivos - México (43,9\%) e Brasil (24,5\%) -, ambos os países têm adotado medidas de reabertura gradual da economia que não encontram respaldo nos dados epidemiológicos e nas recomendações da 0MS ${ }^{24}$ Essa testagem deficitária, verificada em outras nações latino-americanos, aliada à priorização do diagnóstico laboratorial para os sintomáticos graves, pode explicar a incidência acumulada e a taxa de mortalidade acima do esperado, na comparação com outros países cuja taxa de testagem é similar.

A baixa taxa de testagem é um dos fatores que pode resultar na subestimação do número de infectados e, consequentemente, na menor qualidade dos indicadores de saúde., ${ }^{2,7}$ Estudos vêm apontando que a taxa de mortalidade seria um indicador mais fidedigno, frente à taxa de incidência e letalidade,, 27 pois geralmente há maior subestimação no número de casos de infecção por SARS-CoV-2 que no número de óbitos pela COVID-19. ${ }^{20}$

Uma testagem adequada, ao incluir indivíduos sintomáticos leves e assintomáticos, é crucial para a determinação precisa e válida dos indicadores de saúde. Estudo de predição sobre dados de 42 países, publicado no início de abril de 2020, mostrou que um aumento de $10 \%$ na testagem para SARS-CoV-2 levaria a um incremento de aproximados $9 \%$ no número de novos casos, e a uma redução de $9 \%$ na letalidade. ${ }^{28}$ Por meio de análise gráfica, outro estudo verificou que a estratégia de testagem realizada na Itália identificou uma parcela importante da diferença entre a letalidade nesse e em outros países, como a China. ${ }^{29}$
A suposta mudança de uma política de testagem mais restrita (que privilegia pessoas com sintomas graves, contato prévio com caso confirmado, pertencimento a um grupo de 'alto risco'; ou a combinação desses e outros critérios) ${ }^{6}$ para outra com critérios mais amplos e realização de testes em massa na população, resultaria em maior detecção de infectados por SARS-CoV-2, impactando diretamente na melhor qualidade dos indicadores de saúde. Tal mudança, ademais, culminaria em uma maior incidência e maior mortalidade por COVID-19.

É sempre oportuno lembrar o importante papel da vigilância epidemiológica na qualidade dos indicadores de COVID-19, essencial para se obter uma informação acurada e desenhar um panorama real do problema de saúde, as ações e intervenções necessárias para sua abordagem e resolução. A vigilância epidemiológica, especialmente, é capaz de auxiliar na identificação de casos de COVID-19, mediante vigilância de contatos de casos diagnosticados e de casos suspeitos, vigilância ativa no nível da Atenção Primária do Sistema Único de Saúde (SUS) e conscientização da importância da notificação rápida e correta dos casos identificados pelos profissionais envolvidos no combate à pandemia. Dessa forma, a qualidade dos indicadores de saúde também é influenciada - e fortemente - pelas ações de vigilância epidemiológica, essenciais para a saúde pública. $^{30}$

Não obstante trazer importantes reflexões sobre 0 impacto da testagem laboratorial nos indicadores de acompanhamento da pandemia da COVID-19, o presente estudo apresenta algumas limitações. A primeira delas, a qualidade dos dados disponíveis, que não discriminam o tipo de teste realizado (RT-PCR ou teste sorológico). Alguns países fazem uso de ambos os testes, com diferentes finalidades: enquanto o RT-PCR é realizado para diagnosticar infecções ativas, os testes sorológicos servem ao monitoramento de infecções passadas. Contudo, não é possível ter certeza de que esses testes foram adequadamente utilizados. A segunda limitação do estudo encontra-se na dificuldade em comparar dados de países que adotam diferentes estratégias de testagem, com maior ou menor participação dos testes sorológicos no total de casos confirmados. Uma vez que o SARS-CoV-2 é um agente infeccioso emergente e os ensaios disponíveis, todavia, não são totalmente acurados para diagnosticar a infecção, os resultados laboratoriais podem ser pouco consistentes, 
tornando estas conclusões limitadas. Uma terceira limitação do estudo consiste em que mesmo estratégias bastante amplas de testagem, como as adotadas em alguns países asiáticos, não testam absolutamente todos os sujeitos. Considerando-se que uma parte importante dos infectados desenvolve infecção subclínica, todos os indicadores apresentados podem se encontrar sub (incidência acumulada) ou superestimados (taxa de mortalidade e letalidade). Como quarta e última limitação a considerar, há de se ter em conta que os casos não refletem unicamente aqueles diagnosticados por testes laboratoriais. Alguns países adotaram critérios clínico-epidemiológicos em sua definição de caso, o que pode confundir ainda mais os resultados encontrados.

Apesar da heterogeneidade identificada na taxa de testagem da população e das inconsistências nos dados, os resultados da pesquisa indicam que a grande maioria dos países não testa o suficiente para garantir a qualidade dos indicadores de saúde relativos à COVID-19 que permitam planejar o retorno à normalidade de forma segura. Baixas taxas de testagem podem ter, como consequência, a subestimação do número de infectados por SARS-CoV-2 e de óbitos por COVID-19. Gestores de serviços de saúde precisam estar atentos ao reflexo da testagem e vigilância da infecção na qualidade dos indicadores de saúde e seu impacto no planejamento de ações em saúde. Faz-se necessária, portanto, a disponibilização de maior número de testes à população, de maneira a se monitorar adequadamente a magnitude da epidemia. Somente a partir de dados confiáveis, políticas de reabertura econômica serão planejadas de maneira responsável e segura para a sociedade, diminuindo a chance de novas ondas de transmissão do vírus e disseminação da doença.

Conclui-se que tão somente a disponibilização de maior número de testes à população é insuficiente para melhorar a qualidade dos indicadores de saúde. Essa estratégia deve-se acompanhar de outras medidas, como 0 isolamento dos casos diagnosticados e 0 rastreamento de seus respectivos contatos. Para que isso aconteça, é importante que a atenção primária e a Vigilância em Saúde do SUS estejam bem estruturadas. Países como o Brasil, atendido por um sistema de saúde bastante capilarizado, podem se valer da rede já instalada, aqui representada pela Estratégia Saúde da Família, para o acompanhamento dos casos de COVID-19 e mapeamento de seus contatos recentes.

\section{Agradecimentos}

Agradecemos à Rede CoVida por ter propiciado 0 encontro entre os autores, pelas discussões enriquecedoras que fomentaram a idealização do presente trabalho, e pelas sugestões que contribuíram para a melhoria deste artigo em diversos aspectos.

\section{Contribuição dos autores}

Pilecco FB, Coelho CG e Fernandes QHRF participaram da análise e interpretação dos dados e redação do manuscrito. Silveira IH, Pescarini JM, Ortelan N, Gabrielli L, Aquino EML e Barreto ML participaram da revisão crítica relevante do conteúdo intelectual do manuscrito. Todos os autores contribuíram com a concepção e delineamento do estudo, e aprovaram a versão final deste manuscrito, declarando-se responsáveis por todos os aspectos do trabalho.

\section{Referências}

1. Centro Europeu de Prevenção e Controle de Doenças. COVID-19 pandemic [Internet]. Solna: Centro Europeu de Prevenção e Controle de Doenças; 2020 [cited 2020 Aug 20]. Available from: https:// www.ecdc.europa.eu/en/covid-19-pandemic

2. Lachmann A, Jagodnik KM, Giorgi FM, Ray F. Correcting under-reported COVID-19 case numbers: estimating the true scale of the pandemic. medRxiv [Internet]. 2020 Apr [cited 2020 Jun 8]. Available from: https://doi.org/10.1101/2020.03.14.20036178

3. Tang Y-W, Schmitz JE, Persing DH, Stratton CW. Laboratory diagnosis of COVID-19: current issues and challenges. J Clin Microbiol [Internet]. 2020 [cited 2020 Jun 16];58(6):e00512-20. Available from: https://jcm.asm.org/content/58/6/e00512-20

4. Red Argentina Pública de Evaluación de Tecnologías Sanitarias. Diferentes tipos de tests y estrategias diagnósticas en el contexto de pandemia por CoVID-19 [Internet]. [S.1.]: Red Argentina Pública de Evaluación de Tecnologías Sanitarias; 2020 [citado 
2020 jun 8]. Disponível em: http://www.femeba.org. ar/documentos/download/4792-diferentes-tiposde-tests-y-estrategias-diagnosticas-en-el-contextode-pandemia-por-covid-19-redarets-04-2020.pdf

5. Cohen J, Kupferschmidt K. Countries test tactics in 'war' against CoVID-19. Science [Internet]. 2020 Mar [cited 2020 Jun 8];367(6484):12878. Available from: https://www.sciencemag.org/ lookup/doi/10.1126/science.367.6484.1287

6. Richterich P. Severe underestimation of COVID-19 case numbers: effect of epidemic growth rate and test restrictions. medRxiv [Internet]. $2020 \mathrm{Apr}$ [cited 2020 Jun 8]. Available from: http://medrxiv. org/lookup/doi/10.1101/2020.04.13.20064220

7. Rajgor DD, Lee MH, Archuleta S, Bagdasarian N, Quek SC. The many estimates of the COVID-19 case fatality rate. Lancet Infect Dis [Internet]. $2020 \mathrm{Jul}$ [cited 2020 Jun 8]:20(7):776-7. Available from: https://doi.org/10.1016/S1473-3099(20)30244-9

8. Wickham H. ggplot2: elegant graphics for data analysis. 2nd ed. Cham: Springer; 2016.

9. R Core Team. R: A language and environment for statistical computing [Internet]. Vienna, Austria: R Foundation for Statistical Computing; 2020 [cited 2020 Dec 8]. Available from: https://www.R-project.org/

10. Martínez-Anaya C, Ramos-Cervantes P, Vidaltamayo R. Coronavirus, diagnóstico y estrategias epidemiológicas contra COVID-19 en México. Educación Química [Internet]. 2020 [citado 2020 jun 8];31(2):12-22. Disponível em: http://dx.doi. org/10.22201/fq.18708404e.2020.2.75378

11. Organização Mundial de Saúde - OMS. WHO delegation concludes COVID-19 technical mission to Egypt [Internet]. Cairo: Organização Mundial de Saúde Escritório Regional para o Mediterrâneo Oriental; 2020 [citado 2020 jun 15]. Available from: http:// www.emro.who.int/media/news/who-delegationconcludes-covid-19-technical-mission-to-egypt.html

12. Onyeaghala AA, Olajide I. Managing COVID-19 outbreak in Nigeria: matters arising. Clin Chem Lab Med [Internet]. 2020 Jul [cited 2020 Jul 21];58(10):1645-50. Available from: https://doi.org/10.1515/cclm-2020-0748

13. Shammah A, Budoor H, Suad M, Alahmadi, Richard $\mathrm{K}$, Maha $\mathrm{S}$, et al. Middle east respiratory syndrome corona virus (MERS-CoV): levels of knowledge and Awareness in Bahrain. KLS [Internet]. 2018 0ct [cited 2020 Aug 24];4(6):98. Available from: https://doi.org/10.18502/kls.v4i6.3094
14. Organização Mundial de Saúde - OMS. Report of the WHO-China joint mission on coronavirus disease 2019 (COVID-19) [Internet]. Genebra: Organização Mundial de Saúde; 2020 [cited 2020 Jun 15]. Available from: https://www.who.int/docs/default-source/coronaviruse/ who-china-joint-mission-on-covid-19-final-report.pdf

15. Cousins S. New Zealand eliminates COVID-19. Lancet [Internet]. 2020 May [cited 2020 Jun 15];395(10235):1474. Available from: https:// doi.org/10.1016/S0140-6736(20)31097-7

16. Gudbjartsson DF, Helgason A, Jonsson H, Magnusson OT, Melsted P, Norddahl GL, et al. Spread of SARS-CoV-2 in the Icelandic population. N Engl J Med [Internet]. 2020 Jun [cited 2020 Aug 24];382(24):2302-15. Available from: http:// www.nejm.org/doi/10.1056/NEJMoa2006100

17. Wang Y, Kang H, Liu X, Tong Z. Combination of RT-qPCR testing and clinical features for diagnosis of COVID-19 facilitates management of SARSCoV-2 outbreak. J Med Virol [Internet]. 2020 Feb [cited 2020 0ct 19];92(6):538-9. Available from: https://doi.org/10.1002/jmv.25721

18. Promislow DEL. A geroscience perspective on COVID-19 mortality. J Gerontol [Internet]. 2020 Apr [cited 2020 Jul 22];75(9):e30-3. Available from: https://doi.org/10.1093/gerona/glaa094

19. Yang J, Zheng Y, Gou X, Pu K, Chen Z, Guo Q, et al. Prevalence of comorbidities and its effects in patients infected with SARS-CoV-2: a systematic review and meta-analysis. Int $J$ Infect Dis [Internet]. 2020 Mar [cited 2020 Jul 22];94:91-5. Available from: https://doi.org/10.1016/j.ijid.2020.03.017

20. Rudnicki WR, Piliszek R. Estimate of Covid-19 prevalence using imperfect data. medRxiv [Internet]. 2020 Apr [cited 2020 Jun 9]. Available from: https://doi.org/10.1101/2020.04.14.20064840

21. Boccia S, Ricciardi W, Ioannidis JPA. What other countries can learn from Italy during the COVID-19 pandemic. JAMA Intern Med [Internet]. 2020 Apr [cited 2020 Jun 8];180(7):927-8. Available from: https://jamanetwork.com/journals/ jamainternalmedicine/fullarticle/2764369

22. Worldometers. COVID-19 Coronavirus pandemic [Internet]. [S.1.]: Worldometers; 2020 [cited 2020 Aug 19]. Available from: https:// www.worldometers.info/coronavirus/

23. Moriarty LF, Plucinski MM, Marston BJ, Kurbatova EV, Knust B, Murray EL, et al. Public health responses to COVID-19 outbreaks on cruise ships 
— worldwide, February-March 2020. MMWR

Morb Mortal Wkly Rep [Internet]. 2020 Mar

[cited 2020 Jun 8];69(12):347-52. Available from:

http://dx.doi.org/10.15585/mmwr.mm6912e3

24. Johns Hopkins Coronavirus Resource Center.

Which U.S. States meet Recommended

positivity levels? [Internet]. Baltimore: Johns

Hopkins Coronavirus Resource Center; 2020

[cited 2020 Aug 19]. Available from: https://

coronavirus.jhu.edu/testing/testing-positivity

25. Agren D. Mexican president López Obrador draws doctors' ire. Lancet [Internet]. 2020 May [cited 2020 Jul 16];395(10237):1601. Available from: https://doi.org/10.1016/S0140-6736(20)31198-3

26. The Lancet. COVID-19 in Brazil: "So what?" Lancet [Internet]. 2020 May [cited $2020 \mathrm{Aug}$ 19];395(10235):1461. Available from: https:// doi.org/10.1016/S0140-6736(20)31095-3

\section{Abstract}

objective: To analyse how testing the population influences the bealth indicators used to monitor the COVID-19 pandemic in the 50 countries with the highest number of diagnosed cases. Methods: This was an ecological study using secondary data retrieved on 8/19/2020. Cumulative incidence, mortality rate, case-fatality rate, and proportion of positive tests were calculated. The data were described and presented graphically, with their respective Spearman Correlation Coefficients. Results: The testing rate varied enormously between countries. Cumulative incidence and the proportion of positive tests were correlated with the number of tests, while the mortality rate and casefatality rate showed low correlation with this indicator. Conclusion: Most countries do not test enough to ensure adequate monitoring of the pandemic, and this is reflected in the quality of the indicators. Expanding the number of tests is essential, but it needs to be accompanied by other measures, such as isolation of diagnosed cases and contact tracing.

Keywords: Coronavirus Infections; Health Status Indicators; Incidence; Mortality; Betacoronavirus.
27. Hallal PC. Worldwide differences in COVID-19-related mortality. Ciênc saúde coletiva [Internet]. 2020 Jun [cited 2020 Jun 8];25(suppl 1):2403-10. Available from: https://doi.org/10.1590/1413-81232020256.1.11112020

28. Asahi K, Undurraga EA, Wagner R. Benchmarking the CoVID-19 pandemic across countries and states in the USA under heterogeneous testing. medRxiv [Internet]. 2020 May [cited 2020 Jun 8]. Available from: http:// medrxiv.org/lookup/doi/10.1101/2020.05.01.20087882

29. Barone-Adesi F, Ragazzoni L, Schmid M. Investigating the determinants of high case-fatality rate for coronavirus disease 2019 in Italy. Disaster Med Public Health Prep [Internet]. 2020 Apr [cited 2020 Jun 8];1-2. Available from: https://doi.org/10.1017/dmp.2020.106

30. Ibrahim NK. Epidemiologic surveillance for controlling Covid-19 pandemic: types, challenges and implications. J Infect Public Health [Internet]. 2020 Nov [cited 2020 0ct 2];13(11):1630-8. Available from: https://doi.org/10.1016/j.jiph.2020.07.019

\section{Resumen}

objetivo: Analizar cómo el testeo poblacional influye en los indicadores de salud utilizados para monitorear la pandemia de COVID-19 en los 50 países con mayor número de casos diagnosticados. Métodos: Estudio ecológico, con datos secundarios, recogidos el 19/8/2020. Se calcularon la incidencia acumulada, la tasa de mortalidad, la letalidad y la proporción de pruebas positivas. Los datos fueron descritos $y$ presentados gráficamente, con el respectivo Coeficiente de Correlación de Spearman. Resultados: La tasa de testeo varió enormemente entre los países. La incidencia acumulada y la proporción de pruebas positivas se correlacionaron con el número de pruebas, mientras que la tasa de mortalidad y de letalidad mostraron una baja correlación con este indicador. Conclusión: La mayoría de los países no realizan suficientes pruebas para garantizar un seguimiento adecuado de la pandemia, lo que se refleja en la calidad de los indicadores. La ampliación del número de pruebas es fundamental, $y$ debe ir acompañada de aislamiento de casos y seguimiento de contactos.

Palabras clave: Infecciones por Coronavirus; Indicadores de Salud; Incidencia; Mortalidad; Betacoronavirus.

Recebido em 08/09/2020

Aprovado em 25/11/2020

Editora geral: $\quad$ Leila Posenato Garcia - (1) orcid.org/0000-0003-1146-2641

Editoras associadas: Luciana Guerra Gallo - (1) orcid.org/0000-0001-8344-9951

Taís Freire Galvão - (D) orcid.org/0000-0003-2072-4834 